\title{
Investigation on the behaviour of austenite and ferrite phases at stagnation region in the turning of duplex stainless steel alloys
}

\author{
J. Nomani, A. Pramanik*, T. Hilditch, G. Littlefair \\ School of Engineering, Deakin University, Waurn Ponds, Australia \\ *Department of Mechanical Engineering, Curtin University, Bentley, WA, Australia
}

\begin{abstract}
This paper investigates the deformation mechanisms and plastic behaviour of austenite and ferrite phases in duplex stainless steel alloys 2205 and 2507 under chip formation from a machine turning operation. SEM images and EBSD phase mapping of frozen chip root samples detected a build-up of ferrite bands in the stagnation region, between $65-85 \%$ more ferrite was identified in the stagnation region compared to austenite. SEM Images detected micro-cracks developing in the ferrite phase, indicating ferritic build-up in the stagnation region as a potential triggering mechanism to the formation of built-up edge, as transgranular micro-cracks found in the stagnation region are similar to micro-cracks initiating built-up edge formation. Higher plasticity of austenite due to softening under high strain is seen responsible for the ferrite build-up. Flow lines indicate austenite is plastically deforming at a greater rate into the chip, while ferrite shows to partition most of the strain during deformation. The loss of annealing twins and activation of multiple slip planes, triggered at high strain may explain the highly plastic behaviour shown by austenite.
\end{abstract}

Key words: duplex stainless steel, built-up edge, deformation, annealing twins, chip formation,

*Corresponding author

Fax: +61 892662681

Phone: +61 892667981

Email: alokesh.pramanik@,curtin.edu.au 


\subsection{Introduction}

Duplex stainless steels are known in machining for a high tendency to form built-up edge (BUE) on cutting tools. Built-up edge is an undesired effect in machining when the cutting material adheres to the cutting tool. It contributes to poor surface finish and machined dimensional tolerance control, and also accelerated tool wear. Previous machinability studies by the authors [1] identified duplex alloys SAF 2205 \& SAF 2507 had a higher occurrence to built-up edge formation compared to austenite $316 \mathrm{~L}$, causing accelerate tool wear and very poor surface finish. Paro et al. [2] found similar results with drilling cast duplex, finding adhesion wear triggered by built-up edge, as the dominant tool failure mechanism in their machinability study. In an earlier study, Carlborg [3], observed built-up edge to be an issue in turning, and further suggested higher ferrite content in duplex was triggering frequent builtup edge, though no mechanism for this was suggested. Williams reported two-phase materials promote an additional fracture point occurring along the chip-tool rake face during BUE formation, while single phase materials maintain only one fracture point. Williams [4] attributed the fracturing caused by cracking as a result of reduced ductility in the second phase, but could not show how this was occurring. Most machining related studies have mainly focused on the machinability aspect towards machining duplex. There has been little research conducted to focus on understanding the mechanisms triggering these longestablished machinability issues such as built-up edge. The purpose of this paper is to therefore understand the plastic behaviour of the duplex microstructure during chip formation, particularly at the stagnation zone, since it is an area widely known for where built-up edge is most likely to develop. Detail on the plastic flow of the microstructure in this region can provide insight to the triggering mechanisms to frequent built-up edge occurrence.

As a two-phase material, duplex stainless steel combines the inherent benefits of both $\alpha$ ferrite and $\gamma$-austenite phases, in relative equal amounts, see Fig. 1. The $\alpha$-ferrite phase contains a body-centred cubic crystal structure. It is responsible for the excellent pitting and crevice corrosion resistance properties. While the $\gamma$-austenite phase, a face-centred cubic structure promotes the superior strength and toughness [5].

Fig. 1 Microstructure of duplex stainless steel alloy, $\alpha$-ferrite and $\gamma$-austenite phase 
There has been little research focus on observing how these phases behave plastically during chip formation, since both phases naturally respond differently to an applied load. Both $\alpha$ and $\gamma$ obtain different yield strengths [6], with $\gamma$-phase reporting a higher yield [7]. Both phases are also under different pre-strain conditions, ferrite initially under residual compression while austenite under tension. This is attributed to differences in coefficient of thermal expansion [8].

This study focused on two wrought duplex grades, shown in Table. 1. These were used in 'as received' condition, in $\varnothing 20 \mathrm{~mm}$ round-bar form.

Table 1 Nominal chemical composition of test workpiece alloys (wt $\%$ )

\begin{tabular}{llllllllll}
\hline Alloy & $\mathrm{C}$ & $\mathrm{Mn}$ & $\mathrm{Si}$ & $\mathrm{S}$ & $\mathrm{P}$ & $\mathrm{Ni}$ & $\mathrm{Cr}$ & $\mathrm{Mo}$ & $\mathrm{Fe}$ \\
\hline SAF 2507 & 0.02 & 0.74 & 0.23 & 0.01 & 0.02 & 6.77 & 25.1 & 3.68 & Balance \\
SAF 2205 & 0.02 & 0.8 & 0.4 & 0.01 & 0.02 & 5.2 & 22.4 & 3.05 & Balance \\
\hline
\end{tabular}

2.0 Experimental procedure

2.1 Machine turning parameters

Turning experiments were performed on two lathes, a Colchester CNC-2000L machining lathe and a Hafco Metalmaster CL-38 centre lathe. Machining parameters are shown in Table 2. An explosive type quick-stop device, shown in Fig. 2(a), was mounted on each lathe, and was used to produce frozen chip root samples at the indicated machine parameters.

Table 2 Machining parameters

\begin{tabular}{cccc}
\hline Lathe Machine & Cutting speeds & Feed & Condition \\
\hline Colchester & $94 \mathrm{~m} / \mathrm{min}$ & $0.15 \mathrm{~mm} / \mathrm{rev}$ & Dry \\
CNC $-2000 \mathrm{~L}$ & & & \\
\hline Hafco Metalmaster & $74 \mathrm{~m} / \mathrm{min}$ & $0.20 \mathrm{~mm} / \mathrm{rev}$ & Dry \\
CL-38 & $48 \mathrm{~m} / \mathrm{min}$ & & \\
\hline
\end{tabular}

Fig. 2(a) Experimental setup of a quick-experiment (b) sectioned chip root sample 
Solid carbide inserts type WNMG-TF was mounted to the tool holder. These were trigon shaped with $0^{\circ}$ clearance. The produced chip root sample was cut away from the workpiece, using a wet cutting wheel at low rpm. Chips were hot-mounted in PolyFast resin and wet grinding was used to reach the chip root layer.

\subsection{SEM and EBSD preparation and setup}

All samples were prepared by standard polishing procedures, using MD-Mol pads down to $1 \mu \mathrm{m}$ before finishing with OPS type MD-Chem pad. To further reveal phase microstructure under SEM, samples were etched using Beraha's tint etchant, consisting $85 \mathrm{ml}$ of water, $15 \mathrm{ml}$ $\mathrm{HCl}$, 1g K2S2O5. No etching treatment was used on electron backscatter diffraction (EBSD) examined in the SEM samples. These were placed into the SEM chamber un-etched.

SEM scans were taken on a FEI (Philips) XL30 S-FEG high resolution scanning electron microscope. Images were acquired under high current, $10 \mathrm{~mm}$ working distance, $60 \mu \mathrm{m}$ aperture operating at $20 \mathrm{kV}$ accelerating voltage. EBSD scans were performed in a LEO 1530 FEG-SEM high resolution scanning electron microscope, operating at $20 \mathrm{kV}$ and $60 \mu \mathrm{m}$ aperture size. A Nordlys S high CCD detector was used at a $176 \mathrm{~mm}$ insertion distance. The sample was positioned at a $70^{\circ}$ tilt angle. Working distances ranged between $8-12 \mathrm{~mm}$.

The stagnation zone of chip root samples was phase-mapped, using forward scanning detector (FSD) images shown in Fig. 3(a)-(d). Highly strained elongated grains reduced the electron backscatter diffraction pattern (EBSP) quality. Indexing became more difficult as scanning drew nearer towards the tool-chip interface. The use of optimal beam parameters and appropriate data clean-up assisted in obtaining optimal results. Maps were acquired with AZtecHKL software and processed using Channel 5 HKL. All maps were cleaned at 3x zero solutions at level 5 .

Fig. 3. FSD images used for phase mapping. (a) SAF 2205, V=74m/min (b) SAF 2507, $\mathrm{V}=74 \mathrm{~m} / \mathrm{min}$ (c) $\mathrm{SAF} 2205, \mathrm{~V}=48 \mathrm{~m} / \mathrm{min}$ and (d) $\mathrm{SAF} 2507, \mathrm{~V}=48 \mathrm{~m} / \mathrm{min}$; feed $=0.2 \mathrm{~mm} / \mathrm{rev}$

(e) location of FSD scans on chip root sample, the stagnation zone region

3.0 Results 


\subsection{Chip formation}

Fig. 4 shows a sectioned chip root SAF 2205 sample, interrupted at a 94m/min cutting velocity, feed rate $0.15 \mathrm{~mm} / \mathrm{rev}$ and undeformed chip thickness $2.5 \mathrm{~mm}$. The highlighted arrows in Fig. 4(a) shows the material flows into the chip through the primary and secondary shear plane. As both austenite and ferrite phase approach these entry points, they exhibit high deformation due to the high strain. As a result, highly elongated grains develop that skew in the direction of plastic flow, as shown in Fig. 4(b) and 4(c). The highly deformed microstructure would also be an indication that work-hardening has occurred during this transition. The flow pattern of the material is typical in orthogonal metal cutting.

Fig. 4. Scanning Electron Microscope (SEM) images of quick-stop specimen SAF 2205 frozen at speed $94 \mathrm{~m} / \mathrm{min}$, feed $0.15 \mathrm{~mm} / \mathrm{rev}$, undeformed chip thickness $2.0 \mathrm{~mm}$, magnified at various locations $\alpha$-ferrite, $\gamma$-austenite phase (a) overview of chip sample (b) primary shear plane \& (c) secondary shear plane (d) stagnation zone with BUE developing at tip of cutting tool showing micro-cracking patterns (i) intergranular (ii) transgranular

Fig. 5. SEM images of stagnation point on quick-stop specimen SAF 2507 frozen at $\mathrm{V}=94 \mathrm{~m} / \mathrm{min}, \mathrm{f}=0.15 \mathrm{~mm} / \mathrm{rev}$, depth of cut $=2 \mathrm{~mm}$, (a) overview image, (b) secondary shear zone (c) stagnation zone

\subsection{Stagnation zone}

The stagnation zone located at the tip point of the tool region is a common area where the material can remain stationary and does not experience plastic flow for a certain period. Fig. 4(d) shows the stagnation zone for SAF 2205 at high magnification (6000x), where the initial development of a built-up edge layer can be observed. The magnified images revealed the following:

- There is a dominant build-up of ferrite in the stagnation zone region. Although there appears to be visible traces of austenite, the initial built-up layer shows mostly 
comprised of ferrite, according to SEM image in Fig 4(d). This type of banding was also observed in the stagnation region of a 2507 chip root sample produced with the same parameters, see Fig. 5.

- Micro-cracking was found developing in the stagnation region, highlighted in Fig. 4(d). Based on the visible path of crack propagation, these micro-cracks can be described as (i) intergranular, propagating along the primary and sub-grain boundaries, and (ii) transgranular, propagating through the interior of grains. Transgranular cracks appeared more dominant and longer in length, as shown in Fig. 4(d). Some cracks were even found propagating over $30 \mu \mathrm{m}$ in length. Given the larger crack size and angle of crack propagation, a fracture would have occurred across an austenite or ferrite grain. Intergranular cracks appeared smaller in size, while its crack propagation appeared to trace the sub-grain boundaries of the ferrite grains, which is characteristic of an intergranular crack. Motoyashiki et. al, [9] reported similar micro-cracks generating in ferrite grains intergranular slip planes within a ferrite martensitic dual phase steel under cyclic loading. When comparing ferrite-martensite and ferrite-austenite steels, both have similar characteristics. In both cases, ferrite is the softer phase, meanwhile martensite and austenite constitute the hard phase. In a study involving high fatigue cyclic loading of duplex 2205, Dönges [10] reported cracks initiate in the ferrite phase either transgranular along slip planes or intergranular at the interphase boundaries. The transgranular cracking viewed in Fig 4(d) appears to cross both and even shown to extend out towards the chip-tool interface.

\subsection{Phase mapping of the stagnation region}

EBSD phase mapping images shown in Fig. 6 indicated a collection of ferrite build-up in the stagnation zone. Scans of the magnified region revealed a distinguished build-up of ferritic bands accumulating towards the chip tool-interface. The size of the ferrite cluster is shown larger in chip-root samples produced at 48m/min, shown in Figs 6(c) and (d). These regions are compact with ferrite grains and substructures, and appear to accumulate in size during tool advancement.

A comparison of detected phases in the stagnation region compared to the original assupplied microstructure is shown in Fig. 7. The phase count shows the percentage of detected phases is heavily skewed towards the ferrite phase. These values are based on the population 
count of phases in the stagnation zone region, which is the area shown in between the dashed lines in Fig. 6. Both phase maps and populations conclusively show the stagnation region is saturated with the ferrite phase, supporting the existence of a ferrite band region in the stagnation layer.

Fig. 6. Phase map of the stagnation zone on chip root samples (a) SAF $2205, V=74 \mathrm{~m} / \mathrm{min}$ (b) SAF 2507, V = 74m/min (c) SAF 2205, V = 48m/min and (d) SAF 2507, V = 48m/min; feed $=0.2 \mathrm{~mm} / \mathrm{rev}$ for all, (colour map: ferrite red, austenite blue)

Fig. 7. Percentage of detected phases in the stagnation zone

EBSD technique could not phase map grain structures beyond the ferrite band region, due to grains being too plastically deformed to identify. Integrated energy-dispersive spectroscopy (EDS) mapping, also held no solution, due to there being no compositional difference between austenite and ferrite phases. A recent developed mapping solution which could be employed to map this highly strained region, is a method known as DigiSTAR / ASTARTM orientation mapping. A developed transmission electron microscope (TEM) detector sampling method, the technique uses bragg diffraction spots rather than kikuchi band lines to map the crystal orientation, identifying the phase [11]. It has been used in a recent study [12] to successfully phase map severely strained austenite stainless steel $316 \mathrm{~L}$ machined chip samples.

\subsection{Strain calculation in the stagnation zone}

Average strain values were determined by comparing the geometric change in grain size to an unstrained average grain. Long [13] and Chen [14] showed strain values could be approximated by analysing geometric changes in grain structures that were highly deformed during a friction stir welding process. This approach is similar to how strain contouring and 
intergranular misorientation map algorithms calculate strained areas, by contouring according to grain size comparisons to a determined average grain size.

An average grain size was determined based on an adequate sample population size of over 1000 grains, taken at an appropriate scale according to ASTM standard E112, for determining average grain sizes. These average grain size values were generated using Channel 5 HKL software grain size statistics, shown in Table 3

Table 3 Sampled grain sizes of austenite and ferrite phases in as-received condition

\begin{tabular}{cccc}
\hline & \multicolumn{2}{c}{ Average Grain Size } & Sample Population \\
\hline Material & $\begin{array}{c}\text { Ferrite } \\
\boldsymbol{\mu m}^{\mathbf{2}}\end{array}$ & $\begin{array}{c}\text { Austenite } \\
\boldsymbol{\mu m}^{\mathbf{2}}\end{array}$ & Ferrite/ austenite \\
\hline SAF 2205 & 11.218 & 10.695 & $3415 / 4226$ \\
\hline SAF 2507 & 10.563 & 8.672 & $3992 / 4953$ \\
\hline
\end{tabular}

Taking these average values worked out for in the As-Supplied condition for each phase as the original grain size $A_{o}$ then calculating the average grain size value at the stagnation region $A_{f}$, the average true strain $\bar{\varepsilon}$ was then determined by the following equation.

$$
\bar{\varepsilon}=\ln \left(\frac{A_{o}}{A_{f}}\right)
$$

The calculated average strain values displayed in Fig. 8 matched the strain profile of an FEM model observing the same region for austenite stainless steel 316L [15]. Based on these strain values, cutting conditions appeared favourable during higher speed $74 \mathrm{~m} / \mathrm{min}$, with lower strain values. According to Fig. 8 ferrite exhibited higher strain levels in comparison to austenite, under both cutting speeds, $74 \mathrm{~m} / \mathrm{min}$ and $48 \mathrm{~m} / \mathrm{min}$. This appears consistent, since strain would normally partition towards the softer phase.

Fig. 8. Average strain of phases in the stagnation region. 
3.5 Plasticity in the stagnation region

Grain boundary mapping of the stagnation region shown in Fig. 9. reveals a significant change in microstructure in terms of grain size and misorientation. Grain boundary mapping is an effective method used for highlighting areas subject to high strain and deformation. What can be seen in the overview image Fig. 9(a), is the development of sequential stages of strain loading in the duplex microstructure induced by the cutting tool. Annealing twins are a common occurrence in the austenite phase which form as a result of accidential grain growth during grain formation. In an unstrained duplex structure, annealing twins have a widespread appearance in the austenite microstructure [16, 17]. This can be seen at location (i) represented by the blue lines highlighting the high angle grain boundaries (HAGBs). In this area, situated $150 \mu \mathrm{m}$ from the chip-tool interface, the microstructure remains at an unstrained state. Most of detected grain boundaries in this region are austenite annealing twins.

Fig. 9. Grain boundary map of chip root sample material 2507 produced at $V=48 \mathrm{~m} / \mathrm{min}$, $\mathrm{f}=0.20 \mathrm{~mm} / \mathrm{rev}$, depth of cut $=2 \mathrm{~mm}$ (a) Overview image (b) stagnation region. Colour key

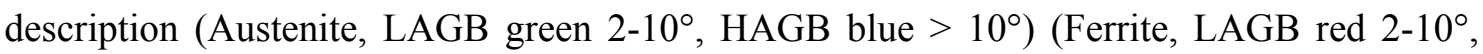
HAGB yellow $>10^{\circ}$ ).

At location (ii), grains begin showing indications of strain loading without exhibiting grain size distortion. But the strain has become large enough to trigger small dislocations in subgrain structures, being detected as low-angle grain boundaries (LAGBs), highlighted in green and red, developing along the grain-boundary lines. Location (ii) would tend to be the point of grains transitioning between elastic and plastic deformation. The greater number of detected LAGBs indicated the level of increasing strain with distance towards the chip-tool interface.

Location (iii) shows the microstructure begin to evolve into heterogeneous structures as a result of high strain. Also referred as lamellar boundaries [18], these dense structures are more suited to handling high strain. They are a combination of high and low angle grain boundaries, compacted together forming an intricate network of grains and substructures. These are shown in more detail in Fig. 9(b). Heterogeneous structures typically form at strain levels $\varepsilon>1$ [18], this agrees with estimated strain figures previously shown in Fig. 8. 
Approaching the stagnation zone, heterogeneous structures become fully developed. The location highlighted (iv) in Fig. 9(b) is fully saturated with heterogeneous structures. These show to reduce in cross-sectional area significantly upon reaching the stagnation zone $(\mathrm{v})$, showing a large banded collection of highly deformed structures. Fig. 10 shows a larger build-up of heterogeneous structures had developed in slower cutting speed chip root sample. The grain boundary map also detected a large cluster of HAGB in the region, particularly for the ferrite phase, highlighted in yellow. Plotted frequency distribution graphs of misorientation shown in Fig. 11, does show the overall count to be greater for the number of LAGB in the stagnation zone. This would be distinguishing for regions of high strain. The grain boundary misorientation distribution profile was found to be identical in all measured chip root samples at the stagnation zone.

Fig. 10. Grain boundary map of chip root sample material 2507 produced at $V=48 \mathrm{~m} / \mathrm{min}$, $\mathrm{f}=0.20 \mathrm{~mm} / \mathrm{rev}$, depth of cut $=2 \mathrm{~mm}$ (ferrite, LAGB red $2-10^{\circ}$, HAGB yellow $>10^{\circ}$ ) (austenite, LAGB green $2-10^{\circ}$, HAGB blue $>10^{\circ}$ )

Fig. 11. Misorientation distribution count of the (a) ferrite phase and (b) austenite phase, distribution colouring (ferrite, LAGB red 2-10 $0^{\circ}$ HAGB yellow $>10^{\circ}$ ) (austenite, LAGB green $2-10^{\circ}$, HAGB blue $>10^{\circ}$ )

\subsection{Austenite annealing twins dissipating ahead of the stagnation zone}

What was evident in the stagnation region was a major decline in the detection of annealing twins in the austenite phase relative to the original unstrained material. The misorientation frequency count graph in Fig. 11 showed a large population decline in the number of high misorientation angles ranging $57.5^{\circ}-60.5^{\circ}$. This reduction was noticed in all chip root samples, see Fig. 12. Wroński [19] commented on the disappearance of annealing twins in the austenite phase in a URN45N duplex tensile sample due to deformation. Wroński also showed that the number of missing twins increased with increasing deformation, though did not disclose what was occurring to the twin boundaries. 
Fig. 12 Austenite grain misorientation distribution for angles $53.5^{\circ}>\theta>62.5^{\circ}$ in duplex stainless alloys

Annealing twins have a $60^{\circ}$ misorientation around the $<111>$ plane. The mapping displayed in Fig. 13 reveals twining boundaries in the chip root sample. The overview mapping image Fig. 13(a) shows the amount of annealing twins becoming fewer in austenite as the microstructure moves closer to the tool interface. The special-boundary map also detected a region of high-angle boundaries which is common under influence of medium to high strain [18], and known to misorientate along the $<111>$ plane [20]. These high angle boundaries appeared in the form of primary slip systems, particularly planar character slip which is common in the austenite phase at high strain and are sometimes referred to as ladders [21] from its distinct progression of parallel slip lines. These slip lines are highlighted in Fig. 13(b). Their appearance are a visible indication of work-hardening. The special-boundary mapping of the stagnation zone, Figs. 13(b) and (c), shows both annealing twins and planar slip lines do not appear stagnation zone region.

Fig. 13. Twin boundary map of 2507 chip root samples (a) overview image of sample frozen at $V=74 \mathrm{~m} / \mathrm{min}$, (b) stagnation zone of sample frozen at $V=74 \mathrm{~m} / \mathrm{min}$ (c) stagnation zone of sample frozen at $\mathrm{V}=48 \mathrm{~m} / \mathrm{min}$ (mapping detection, blue at $\theta=60^{\circ}$ misorientation, at $<111>$ plane)

\subsection{Evolving annealing twin structures}

It is possible the high level of deformation that occurred to the annealing twin structures, had triggered them to misorientate beyond their ideal $60^{\circ}$ misorientation. Given that $60^{\circ}$ is the maximum misorientation angle of detection in the $<111>$ plane since the lowest angle representation is always determined, see Fig 14. Therefore, the twin boundaries have structurally deformed and was now being detected at lower misorientation angles. These twin boundaries are shown to be migrating according to distribution plot in Fig. 11 and are shown to no longer lie on their usual $60^{\circ}$ misorientation axis. 
Fig. 14 Diagram showing maximum possible detection angle of misorientation between grains in crystal structure, $<111>$ crystal rotational axis

To show this was occuring, grain boundary maps detecting misorientations between $\left(20-60^{\circ}\right)$ in the austenite phase, was observed for possible evolved twins. Four possible candidates were found, shown in Fig. 15. These were seen most likely to have been annnealing twins, formed prior to deformation. In each case, parts of the grain boundary was detected as a twin i.e. matching special boundary features. Also, one of the candidate grain boundaries (c), was located parallel to an adjacent grain boundary line, similar to the formation of a twin boundary. Mechanical twins were ruled out since they are more likely produced in larger grain sizes [22], which would not be the case in the stagnation region.

Fig. 15. Tracking evolved austenite twin boundaries; mapping colouring; (austenite, pink $>$ $20^{\circ}$, yellow $>30^{\circ}$, green $>40^{\circ}$, aqua $50^{\circ}>\theta$, blue special boundary $<111>, 60^{\circ}$, ferrite - red)

Fig. 16. Misorientation profiles plotted along evolved twin boundaries at the stagnation zone at locations shown in Fig. 15

Misorientation profiles were plotted in a straight line path from distance $x=0$, to intersect these suspected twin boundaries. These plots shown in Fig. 16 highlights the change in orientation. Boundaries detected between $20-60^{\circ}$ indicates points of intersection, along the suspected evolved twin. The variation from $60^{\circ}$, at these intersecting points, highlights the orientation of the twin boundary has evolved, and is varying at different locations along the boundary line. Dislocations by edge or screw dislocation, would be dislocation mechanisms causing this re-orientation effect.

\subsection{Discussion}

4.1 Ferrite bands triggering the formation of built-up edge 
The identified micro-cracks in the stagnation zone shown previously in Fig. 4 suggests the ferritic bands collecting in the stagnation zone are acting as a triggering mechanism to the promotion of built-up edge. What has been observed in this study from EBSD phase maps and SEM images of the stagnation region is the dominate build-up of ferrite and the existence of micro-cracks. Micro-cracks are a known triggering mechanism for built-up edge [23]. The transgranular micro-crack patterns are similar to micro-cracks observed by Wallbank [24]. In his BUE study, Wallbank [24] traced the origin of shear between the chip and the built-up layer and reported it originating from micro-cracking initiating in the ferrite phase in $0.1 \% \mathrm{C}$ and $0.4 \% \mathrm{C}$ grade steels. A more recent study by Dönges [10] suggests these micro-cracks could be triggered from high-cyclic loading. While observing the plastic behaviour of 2205 duplex under cyclic loading, Dönges reported fatigue cracks frequently initiate transgranular in ferritic slip bands or intergranular at the ferritic phase boundaries. Given that material is potentially not moving in the stagnation zone relative to the cutting tool, the strain paths would still be highly active in the region [15]. The induced loading on the stagnant ferrite bands inhibited by the neighbouring flowing material would similarly generate a high cyclic loading environment. Subsequently triggering micro-cracking, initiating the first stage in the formation of BUE. These ferrite bands acting as a triggering mechanism would support Carlborg's earlier statement, suggesting a higher content of ferrite causes more built-up edge [3].

\subsection{Mechanisms for ferrite build-up}

A number of studies $[7,16,19,25,26]$ have reported that in a duplex stainless material, austenite plastically deforms at a higher degree than ferrite. Johansson [7] observed this through X-ray diffraction (XRD) and transmission electron microscopy (TEM) in a 2304 duplex alloy during cyclic loading. Johansson mentioned that despite austenite obtaining a higher yield and hardness, it still underwent higher plastic deformation than ferrite. Johansson suggested this was due to residual stresses present in the material. Furthermore, Wroński [19] reported austenite has a higher dislocation density than ferrite, indicating the rate at which low angle grain boundaries (LAGB) appear is greater. The grain boundary mapping of the stagnation region detected a large population of LAGB's in both austenite and ferrite which signified the occurrence of high level dislocation, refer to the misorientation frequency plots in Fig. 11. If Wroński's observation is accurate, then the rate of dislocation and related strain that occurs would be increased in the austenite phase. It would explain how ferrite bands are 
collecting, since these bands are deforming to a lesser degree and at a lesser rate than austenite.

Fig. 17. Indicated austenite flow directions in the stagnation region of a 2205 chip root sample, produced at $V=94 \mathrm{~m} / \mathrm{min}$

Therefore, based on the proposed behaviour, the austenite flow paths highlighted in Fig. 17 of a stagnation region would indicate the austenite grains are effectively straining more and at an increased rate than ferrite. These austenite grains would tend to flow at an increased rate into the chip during tool advancement through the primary or secondary shear zone, or separate at lower region and remain compressed as part of the machined surface. Ferritic grains appear to flow in the same directions as austenite but this would be at a relatively slower rate. Given these differences the ferrite would tend to show less deformation being able to withstand more loading, which is seen in Fig. 17 by the display of larger ferrite grains compared to austenite.

\subsection{Austenite phase softening under high strain}

For the austenite phase to plastically deform at a greater degree than ferrite, would imply the austenite phase becomes softer despite austenite being well known for its high workhardening ability $[2,27]$. This austenite softening occurrence is possible as indicated by literature. Studies involving cyclic loading of duplex stainless alloys [28, 29] reported the austenite phase does become softer after work-hardening under increasing strain, and continues to soften until fracture. Mateo [28] indicated the increasing plastic deformation in austenite was due to the activation of new slip systems. This activation of new slip systems, moreover multiple slip systems would be a suitable candidate to explain the plastic softening behaviour in austenite.

Fig. 18. Schematic of slip activation in an austenite grain under loading 
A model based on a tensile study on austenite 316L stainless steel by Feagus [30] was proposed to describe the hardening-softening transition of austenite during plastic deformation. The model ties in the activation of multiple slip with evolved twinning structures, as observed in this study. Annealing twins have been associated to maintaining the initial microstructure. A study by Randle [31] reported the presence of annealing twins act as a barrier for slip motion. Feagus [30] observed back stresses in the form of single slip pileups collect along grain and twinning boundaries. These pileups create intergranular stress concentrations, which the boundaries was reported to withstand up to a maximum strain $\varepsilon_{\max }=1.5$. At which point, multiple slip systems, including cross slip would activate to relieve these stresses, as illustrated in Fig. 18. A known product of cross and multiple slip systems are the formation of heterogeneous structures [18, 32], such as those detected in the stagnation region of chip root samples, see Fig. 9 and Fig. 10. Two studies [25, 32] have related Feagus's multiple slip activation threshold to occur in duplex stainless steel alloys within an austenite phase. Hedström [32] observed the softening occur in single austenitic grains, in a 2304 duplex tensile sample using X-ray diffraction. With the calculated strain averages for austenite shown previously in Fig. 8 being estimated as high as $\varepsilon=2.98$, it is most likely multiple slip systems were activated. However it is evident the actual strain levels triggering multiple slip activation in austenite should be further investigated for duplex stainless alloys.

5.0 Conclusion

This study observed the deformation mechanisms which occur in the stagnation region of chip root samples produced from the turning duplex stainless steel alloys. Observing the microstructure under SEM and EBSD analysis has drawn the following conclusions.

- The ferrite phase was found collecting in the stagnation region in the form of ferritic bands. Phase mapping of SAF 2205 and 2507 chip-root samples detected a higher percentage of ferrite to austenite in the stagnation region, $65-85 \%$ more ferrite. SEM images revealed micro-cracks developing both integranular and transgranular from the ferrite build-up. The micro-crack profiles are similar to those initiating built-up edge formation, concluding ferrite build-up as a potential candidate for triggering of built-up edge formation.

- Grain boundary mapping of the stagnation region, revealed both austenite and ferrite grains developing into heterogeneous structures, in the workpiece microstructure 
leading towards the chip-tool interface. These structure typically form as an adapting mechanism towards handling high strain, typically $\varepsilon>1$. Individual strain calculations of the stagnation region, approximate the strain for both phases to be well above $\varepsilon>1$.

- Annealing twins in the austenite phase disband ahead of the stagnation region. These twinning structures are mis-orientating beyond their ideal $60^{\circ}$ orientation along the $<111>$ plane. As a result, the twinning structures are being detected at lower misorientation angles. Further investigation on observing breakdown of these twinning structures and determining what amount of strain at which this breakdown commences is recommended. TEM studies are in current progress by the authors to quantify the dislocation behaviour of austenite and ferrite phases approaching the stagnation zone during chip form in a duplex stainless workpiece.

- The detection of heterogeneous lamellar structures and re-orientation of annealing twins, indicate dislocation in the austenite phase is occurring by multiple slip systems. This occurrence may explain the ferrite build-up in the stagnation region, caused by the austenite phase softening upon approaching the stagnation zone region. A finite element model is being developed, based on actual physical microstructure to simulate the plastic flow of these two-phases during chip formation.

Acknowledgements:

The authors would like to thank Dr Andrew Sullivan and Dr Mark Nave at the Institute for Frontiers Materials research for their help in the EBSD data acquisition. The authors would also like to thank Mr Rodney Seiffert for his help with the machining experimental work.

\section{References}

1. Nomani, J., et al., Machinability study of first generation duplex (2205), second generation duplex (2507) and austenite stainless steel during drilling process. Wear, 2013. 304(1-2): p. 20-28.

2. Paro, J., H. Hänninen, and V. Kauppinen, Tool wear and machinability of HIPed P/M and conventional cast duplex stainless steels. Wear, 2001. 249(3-4): p. 279-284.

3. Carlborg, C., Machinability of duplex stainless steel. Proceedings of duplex stainless steel, 1991. 1(1): p. 683-96.

4. Williams, J.E. and E.C. Rollason, Metallurgical and Practical Machining Parameters Affecting Built-up Edge Formation in Metal Cutting. Journal of the Institute of Metals, 1970. 98: p. 144-159.

5. Anon, ed. Practical guidelines for the fabrication of duplex stainless steel. 2nd ed. 2009, International Molybdenum Association. 
6. Cho, K. and J. Gurland, The law of mixtures applied to the plastic deformation of two-phase alloys of coarse microstructures. Metallurgical Transactions A, 1988. 19(8): p. 2027-2040.

7. Johansson, J. and M. Odén, Load sharing between austenite and ferrite in a duplex stainless steel during cyclic loading. Metallurgical and Materials Transactions A, 2000. 31(6): p. 15571570.

8. Johansson, J., M. Odén, and X.H. Zeng, Evolution of the residual stress state in a duplex stainless steel during loading. Acta Materialia, 1999. 47(9): p. 2669-2684.

9. Motoyashiki, Y., A. BrüCkner-Foit, and A. Sugeta, Investigation of small crack behaviour under cyclic loading in a dual phase steel with an FIB tomography technique. Fatigue \& Fracture of Engineering Materials \& Structures, 2007. 30(6): p. 556-564.

10. Dönges, B., et al., Significance of crystallographic misorientation at phase boundaries for fatigue crack initiation in a duplex stainless steel during high and very high cycle fatigue loading. Materials Science and Engineering: A, 2014. 589(0): p. 146-152.

11. Rauch, E.F. and M. Véron, Automated crystal orientation and phase mapping in TEM. Materials Characterization, 2014. 98: p. 1-9.

12. Idell, Y., et al., Strengthening of austenitic stainless steel by formation of nanocrystalline $\gamma$ phase through severe plastic deformation during two-dimensional linear plane-strain machining. Scripta Materialia, 2013. 68(9): p. 667-670.

13. Long, T., W. Tang, and A. Reynolds, Process response parameter relationships in aluminium alloy friction stir welds. Science and Technology of Welding \& Joining, 2007. 12(4): p. 311317.

14. Chen, Z. and S. Cui. Strain and strain rate during friction stir welding/processing of Al-7Si-0.3 Mg alloy. in IOP Conference Series: Materials Science and Engineering. 2009. IOP Publishing.

15. Nasr, M.N.A., E.G. Ng, and M.A. Elbestawi, Modelling the effects of tool-edge radius on residual stresses when orthogonal cutting AISI 316L. International Journal of Machine Tools and Manufacture, 2007. 47(2): p. 401-411.

16. Herrera, C., D. Ponge, and D. Raabe, Design of a novel Mn-based 1\&\#xa0;GPa duplex stainless TRIP steel with $60 \%$ ductility by a reduction of austenite stability. Acta Materialia, 2011. 59(11): p. 4653-4664.

17. Jimenez, J.A., et al., Characterization of a $\delta / V$ duplex stainless steel. Journal of Materials Science, 2000. 35(4): p. 907-915.

18. Hughes, D.A. and N. Hansen, High angle boundaries formed by grain subdivision mechanisms. Acta Materialia, 1997. 45(9): p. 3871-3886.

19. Wroński, S., et al., Investigation of plastic deformation heterogeneities in duplex steel by EBSD. Materials Characterization, 2012. 73(0): p. 52-60.

20. Kumar, M., A.J. Schwartz, and W.E. King, Correlating observations of deformation microstructures by TEM and automated EBSD techniques. Materials Science and Engineering: A, 2001. 309-310(0): p. 78-81.

21. Kruml, T. and S. Degallaix, Dislocation structures in the bands of localised cyclic plastic strain in austenitic 316L and austenitic-ferritic duplex stainless steels. Acta materialia, 1997. 45(12): p. $5145-5151$.

22. El-Danaf, E., S. Kalidindi, and R. Doherty, Influence of grain size and stacking-fault energy on deformation twinning in fcc metals. Metallurgical and Materials Transactions A, 1999. 30(5): p. 1223-1233.

23. Iwata, K. and K. Ueda, Fundamental analysis of the mechanism of built-up edge formation based on direct scanning electron microscope observation. Wear, 1980. 60(2): p. 329-337.

24. Wallbank, J., Structure of built-up edge formed in metal cutting. Metals Technology, 1979. 6(1): p. 145-153.

25. Moverare, J.J. and M. Odén, Deformation behaviour of a prestrained duplex stainless steel. Materials Science and Engineering: A, 2002. 337(1-2): p. 25-38. 
26. Moverare, J. and M. OdÃ@n, Influence of elastic and plastic anisotropy on the flow behavior in a duplex stainless steel. Metallurgical and Materials Transactions A, 2002. 33(1): p. 57-71.

27. Dolinsek, S., Work-hardening in the drilling of austenitic stainless steels. Journal of Materials Processing Technology, 2003. 133(1-2): p. 63-70.

28. Mateo, A., et al., Cyclic stress-strain response and dislocation substructure evolution of a ferrite-austenite stainless steel. Acta Materialia, 1996. 44(3): p. 1143-1153.

29. Obrtlík, K., T. Kruml, and J. Polák, Dislocation structures in 316L stainless steel cycled with plastic strain amplitudes over a wide interval. Materials Science and Engineering: A, 1994. 187(1): p. 1-9.

30. Feaugas, X., On the origin of the tensile flow stress in the stainless steel AISI $316 \mathrm{~L}$ at $300 \mathrm{~K}$ : back stress and effective stress. Acta Materialia, 1999. 47(13): p. 3617-3632.

31. Randle, V., Mechanism of twinning-induced grain boundary engineering in low stacking-fault energy materials. Acta Materialia, 1999. 47(15-16): p. 4187-4196.

32. Hedström, P., et al., Load partitioning between single bulk grains in a two-phase duplex stainless steel during tensile loading. Acta Materialia, 2010. 58(2): p. 734-744.

\section{List of figures:}

Fig. 1 Microstructure of duplex stainless steel alloy, $\alpha$-ferrite and $\gamma$-austenite phase

Fig. 2(a) Experimental setup of a quick-experiment (b) sectioned chip root sample

Fig. 3. FSD images used for phase mapping. (a) SAF 2205, V=74m/min (b) SAF 2507, $\mathrm{V}=74 \mathrm{~m} / \mathrm{min}$ (c) SAF 2205, V=48m/min and (d) SAF $2507, \mathrm{~V}=48 \mathrm{~m} / \mathrm{min}$; feed = $0.2 \mathrm{~mm} / \mathrm{rev}$ (e) location of FSD scans on chip root sample, the stagnation zone region

Fig. 4. Scanning Electron Microscope (SEM) images of quick-stop specimen SAF 2205 frozen at speed $94 \mathrm{~m} / \mathrm{min}$, feed $0.15 \mathrm{~mm} / \mathrm{rev}$, undeformed chip thickness $2.0 \mathrm{~mm}$, magnified at various locations $\alpha$-ferrite, $\gamma$-austenite phase (a) overview of chip sample (b) primary shear plane \& (c) secondary shear plane (d) stagnation zone with BUE developing at tip of cutting tool showing micro-cracking patterns (i) intergranular (ii) transgranular

Fig. 5. SEM images of stagnation point on quick-stop specimen SAF 2507 frozen at $\mathrm{V}=94 \mathrm{~m} / \mathrm{min}, \mathrm{f}=0.15 \mathrm{~mm} / \mathrm{rev}$, depth of cut $=2 \mathrm{~mm}$, (a) overview image, (b) secondary shear zone (c) stagnation zone

Fig. 6. Phase map of the stagnation zone on chip root samples (a) SAF $2205, V=74 \mathrm{~m} / \mathrm{min}$ (b) SAF 2507, V = 74m/min (c) SAF 2205, V = 48m/min and (d) SAF 2507, V = $48 \mathrm{~m} / \mathrm{min}$; feed $=0.2 \mathrm{~mm} / \mathrm{rev}$ for all, (colour map: ferrite red, austenite blue) 
Fig. 7. Percentage of detected phases in the stagnation zone

Fig. 8. Average strain of phases in the stagnation region.

Fig. 9. Grain boundary map of chip root sample material 2507 produced at $V=48 \mathrm{~m} / \mathrm{min}$, $\mathrm{f}=0.20 \mathrm{~mm} / \mathrm{rev}$, depth of cut $=2 \mathrm{~mm}$ (a) Overview image (b) stagnation region. Colour key description (Austenite, LAGB green $2-10^{\circ}$, HAGB blue $>10^{\circ}$ ) (Ferrite, LAGB red 2-10 $0^{\circ}$ HAGB yellow $>10^{\circ}$ ).

Fig. 10. Grain boundary map of chip root sample material 2507 produced at $V=48 \mathrm{~m} / \mathrm{min}$, $\mathrm{f}=0.20 \mathrm{~mm} / \mathrm{rev}$, depth of cut $=2 \mathrm{~mm}$ (ferrite, LAGB red $2-10^{\circ}$, HAGB yellow $>10^{\circ}$ ) (austenite, LAGB green $2-10^{\circ}$, HAGB blue $>10^{\circ}$ )

Fig. 11. Misorientation distribution count of the (a) ferrite phase and (b) austenite phase, distribution colouring (ferrite, LAGB red 2-10 , HAGB yellow $>10^{\circ}$ ) (austenite, LAGB green $2-10^{\circ}, \mathrm{HAGB}$ blue $>10^{\circ}$ )

Fig. 12 Austenite grain misorientation distribution for angles $53.5^{\circ}>\theta>62.5^{\circ}$ in duplex stainless alloys

Fig. 13. Twin boundary map of 2507 chip root samples (a) overview image of sample frozen at $V=74 \mathrm{~m} / \mathrm{min}$, (b) stagnation zone of sample frozen at $\mathrm{V}=74 \mathrm{~m} / \mathrm{min}$ (c) stagnation zone of sample frozen at $\mathrm{V}=48 \mathrm{~m} / \mathrm{min}$ (mapping detection, blue at $\theta=60^{\circ}$ misorientation, at $<111>$ plane)

Fig. 14 Diagram showing maximum possible detection angle of misorientation between grains in crystal structure, $<111>$ crystal rotational axis

Fig. 15. Tracking evolved austenite twin boundaries; mapping colouring; (austenite, pink > $20^{\circ}$, yellow $>30^{\circ}$, green $>40^{\circ}$, aqua $50^{\circ}>\theta$, blue special boundary $<111>, 60^{\circ}$, ferrite - red)

Fig. 16. Misorientation profiles plotted along evolved twin boundaries at the stagnation zone at locations shown in Fig. 15

Fig. 17. Indicated austenite flow directions in the stagnation region of a 2205 chip root sample, produced at $V=94 \mathrm{~m} / \mathrm{min}$

Fig. 18. Schematic of slip activation in an austenite grain under loading 


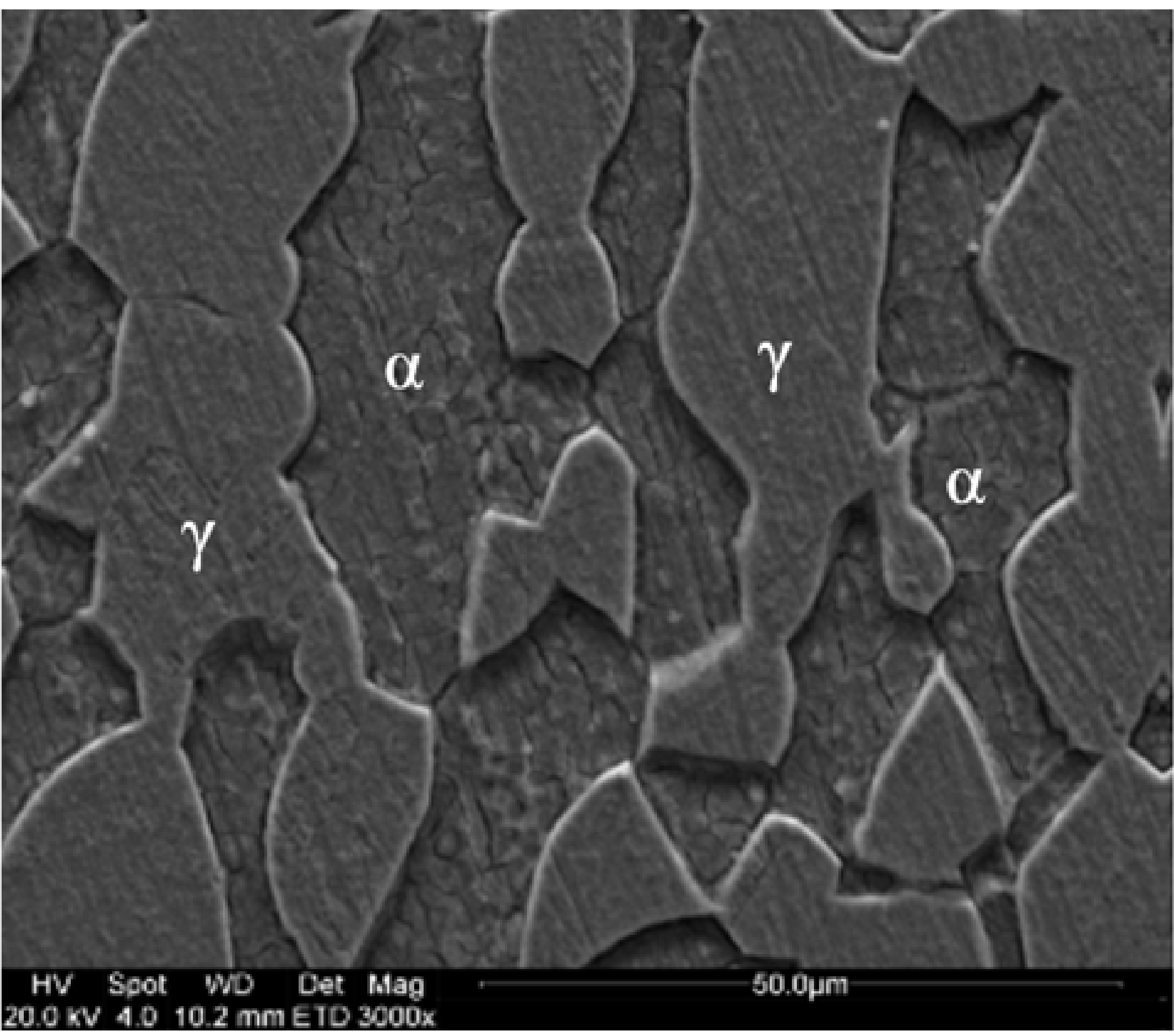




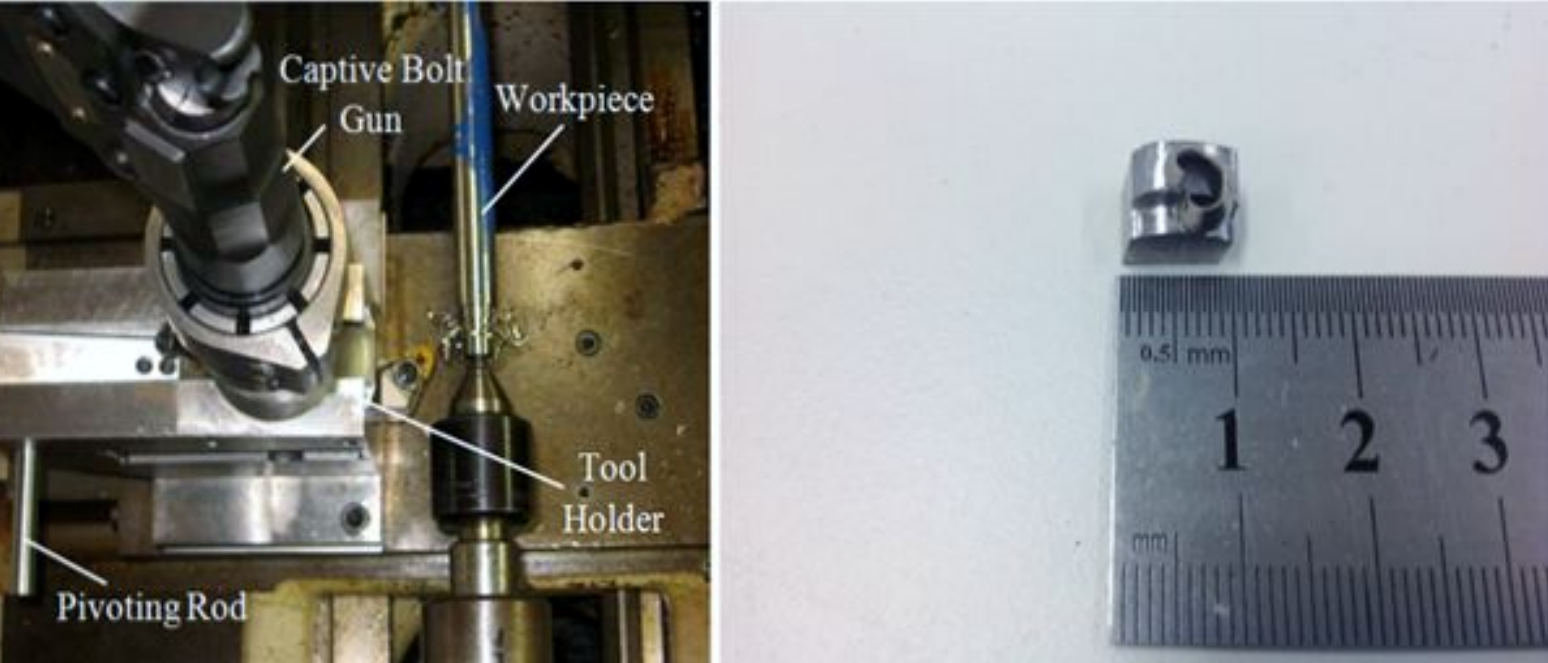




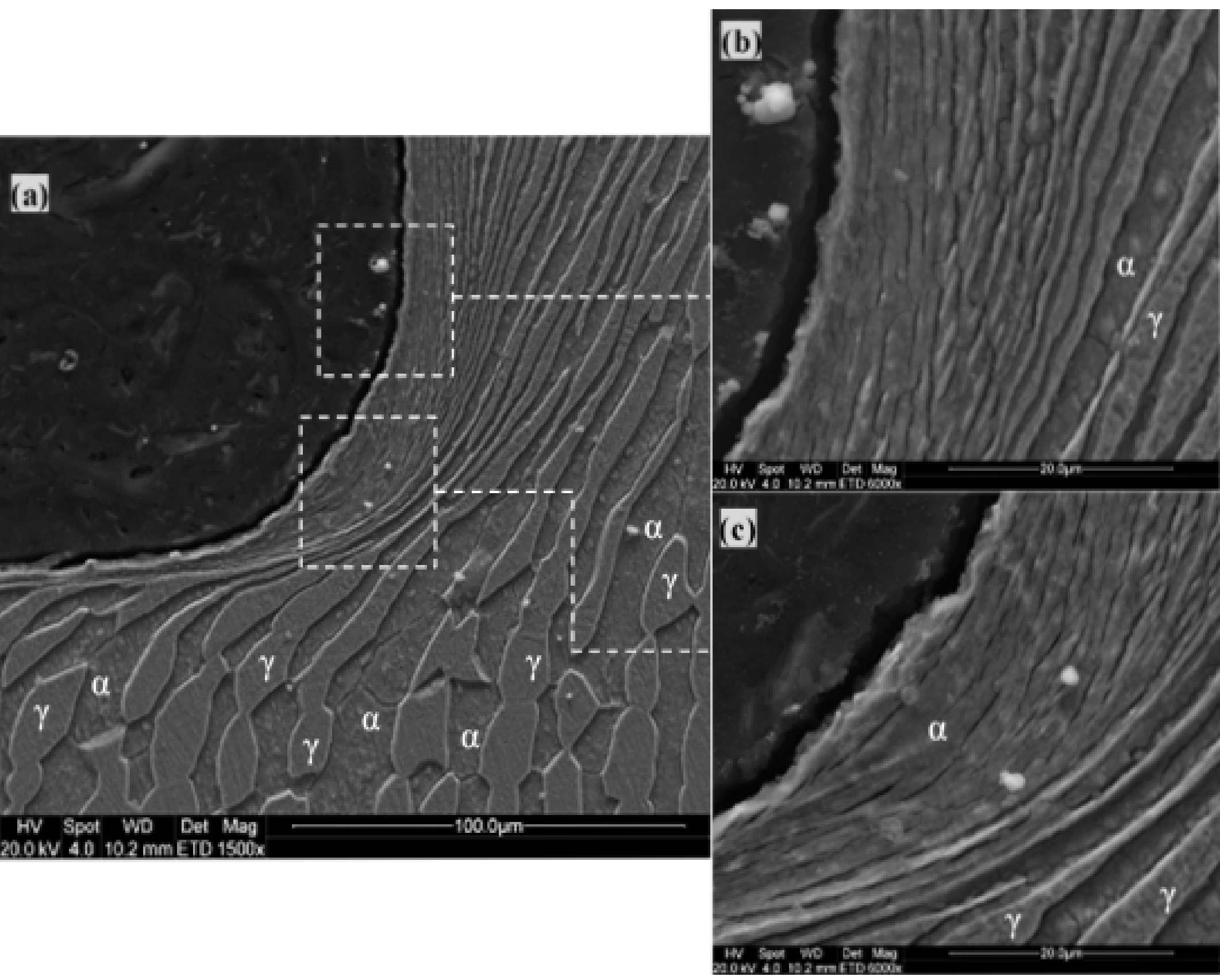




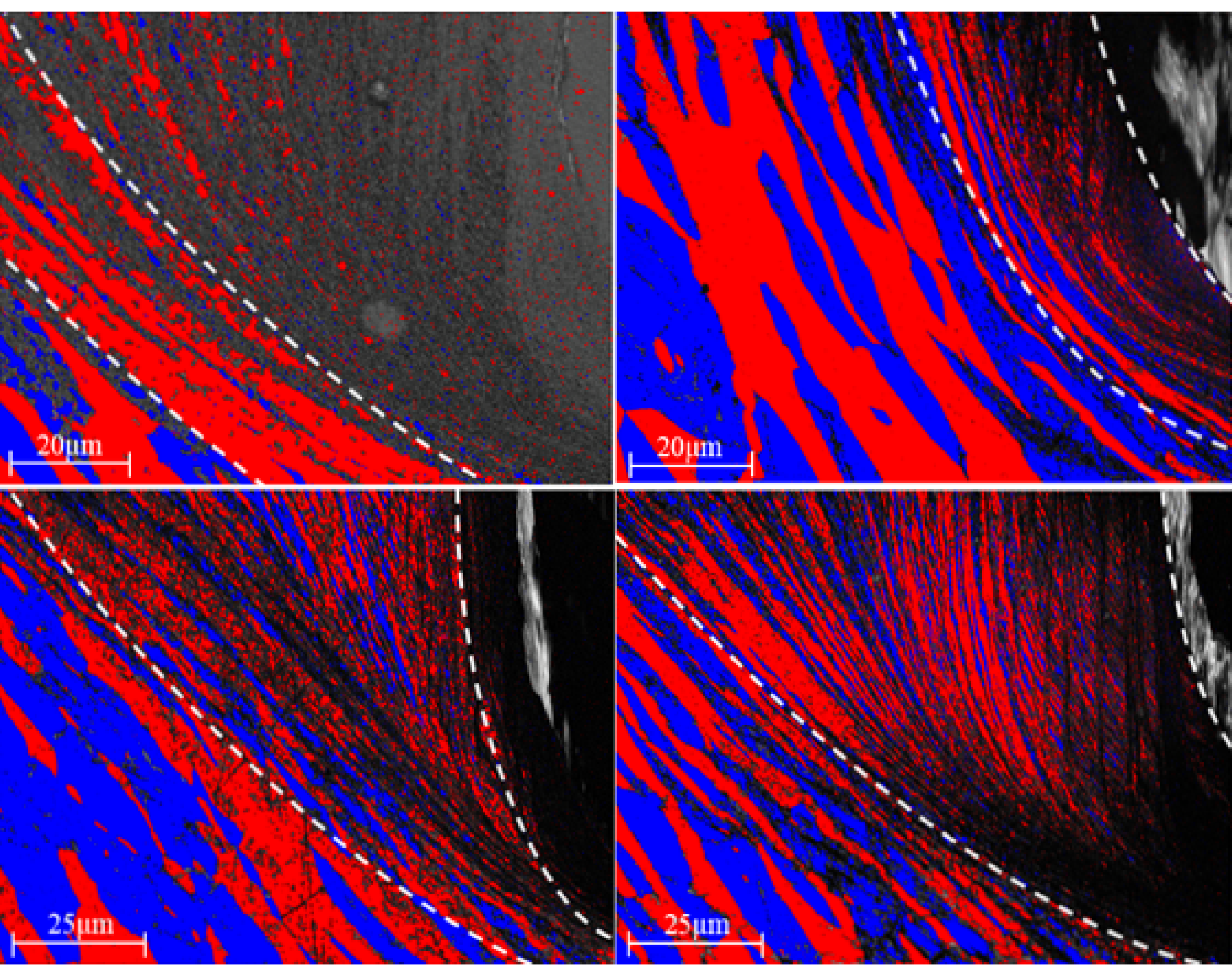


$2205,74 \mathrm{~m} / \mathrm{min}$

$2507,74 \mathrm{~m} / \mathrm{min}$

$2205,48 \mathrm{~m} / \mathrm{min}$

$2507,48 \mathrm{~m} / \mathrm{min}$

2205, As-supplied

2507, As-supplied

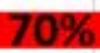

$72 \%$

$45 \%$

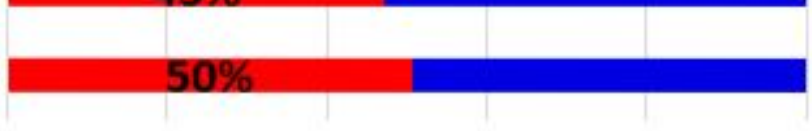

$\begin{array}{llllll}0 \% & 20 \% & 40 \% & 60 \% & 80 \% & 100 \%\end{array}$

- Ferrite Austenite 

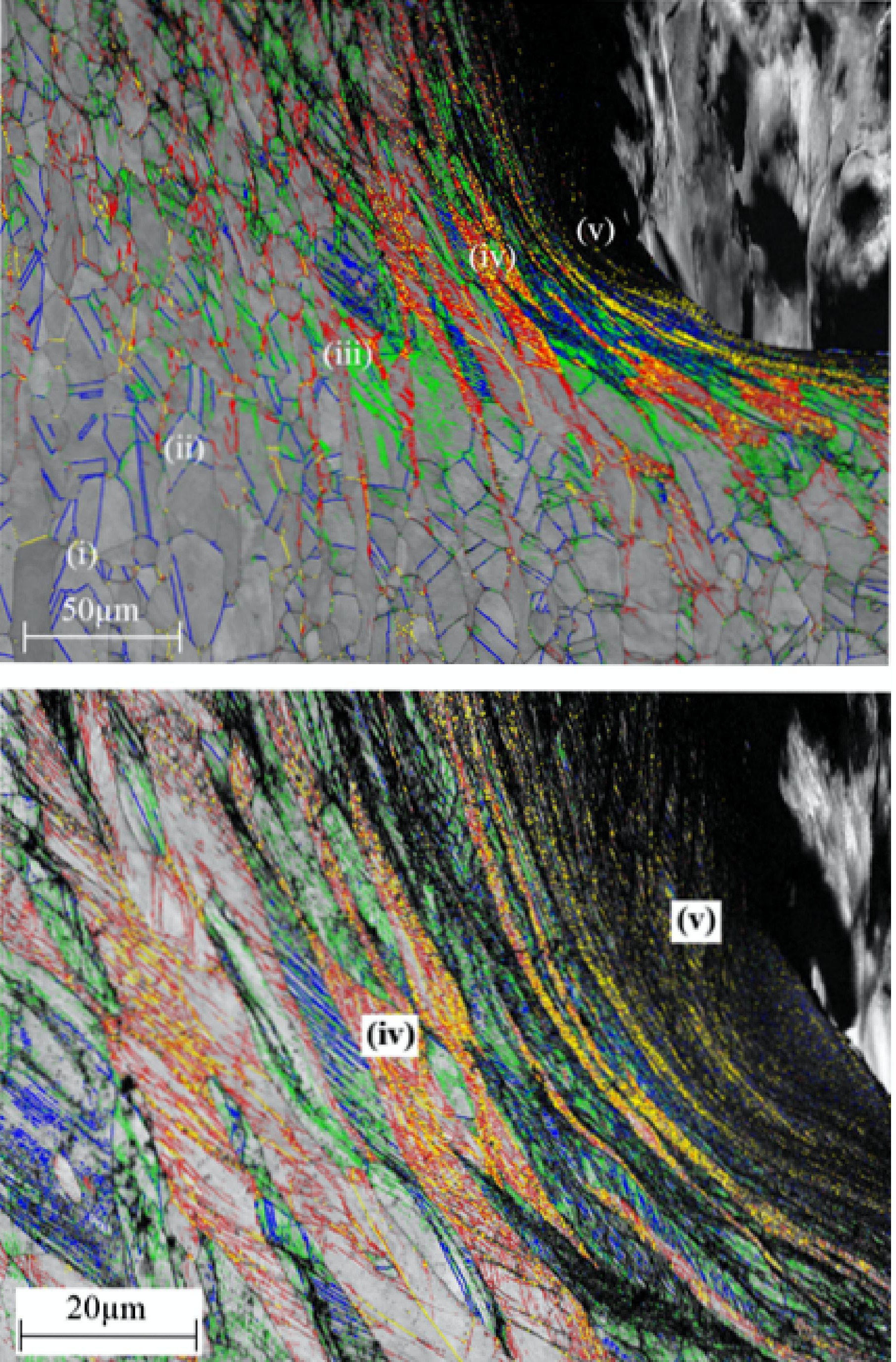


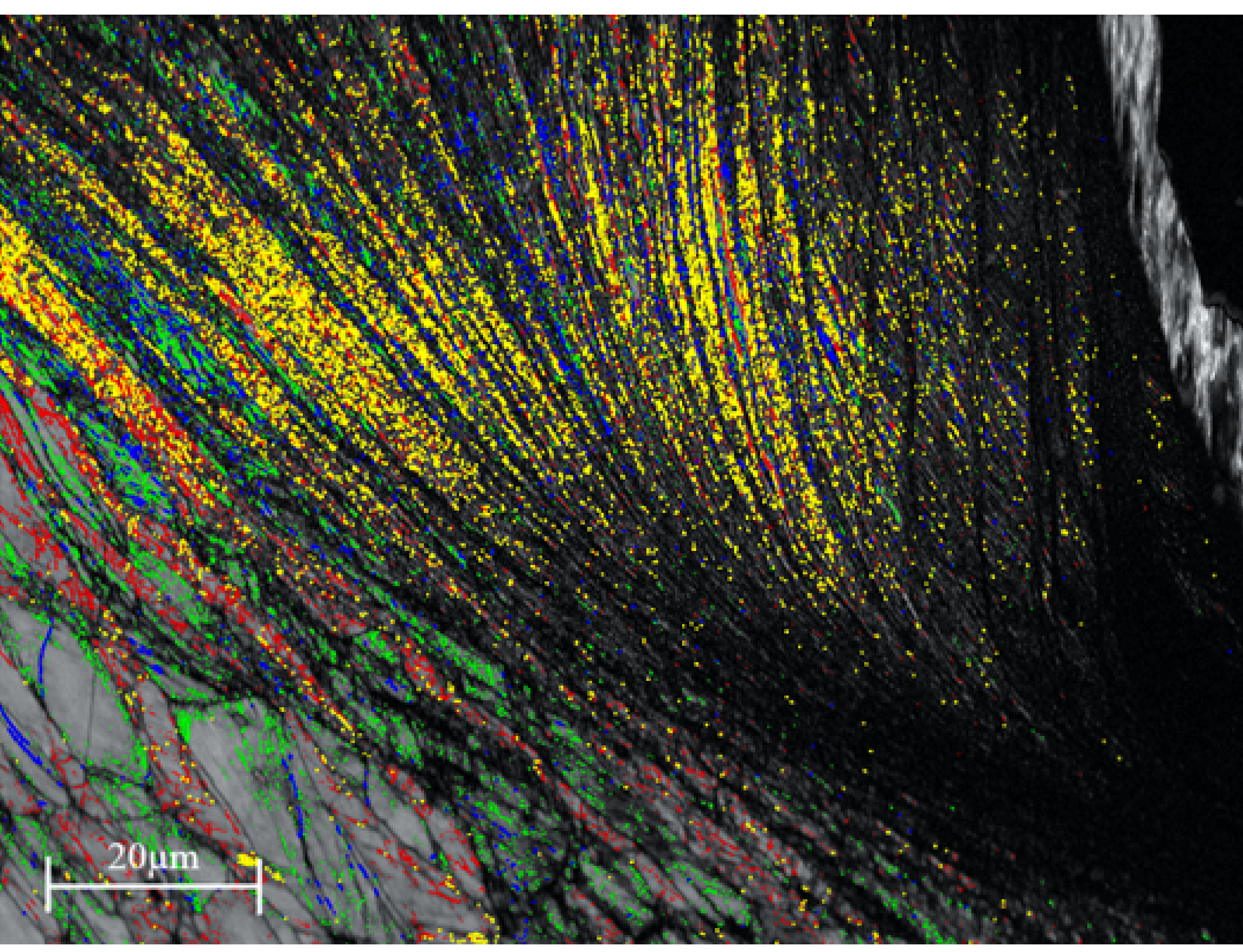




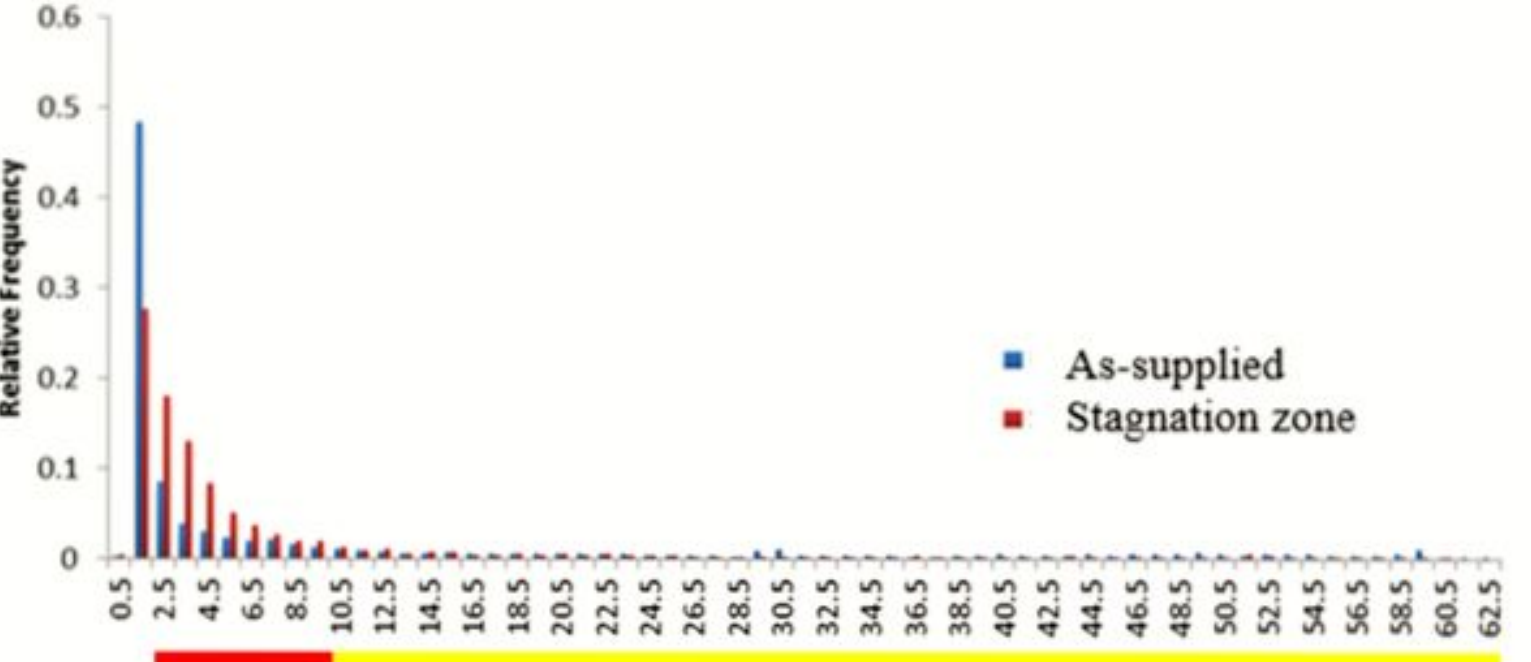

\section{Misorientation ( ${ }^{\circ}$ )}

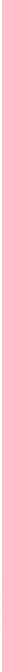



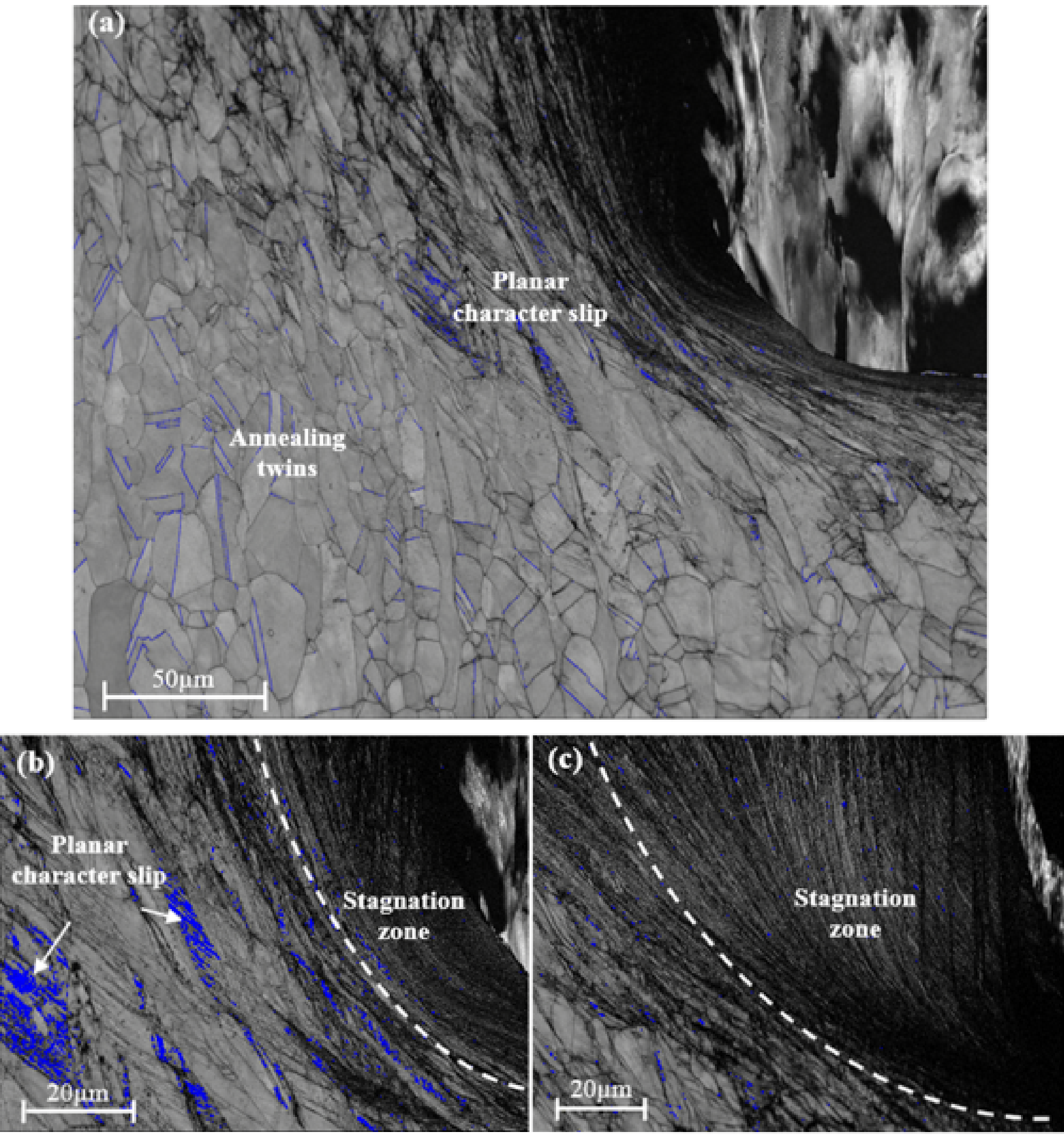
Misorientation angle $=0^{\circ}$

Misorientation angle $=60^{\circ}$
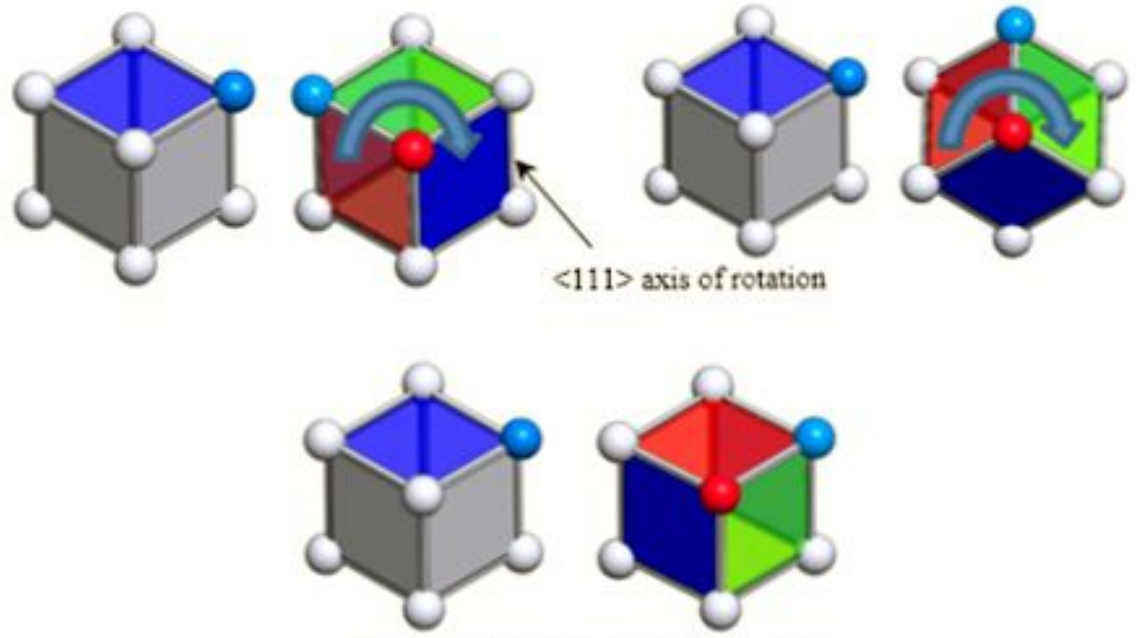

Misorientation angle $=0^{\circ}$ 
(a)

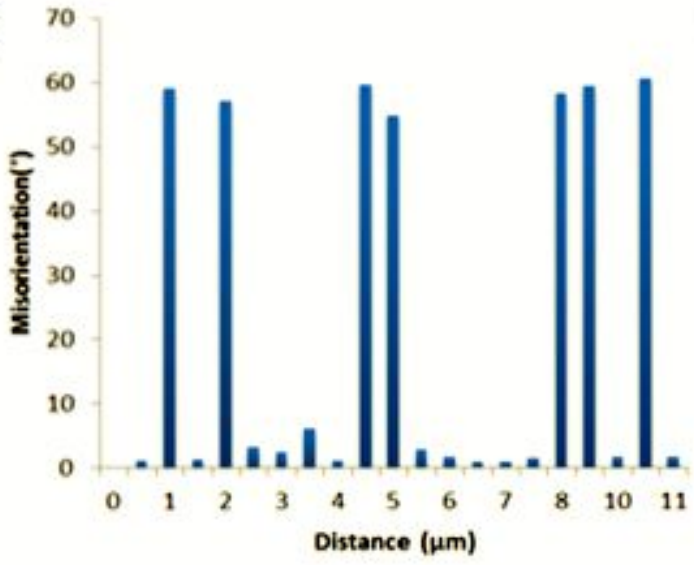

(c) 70

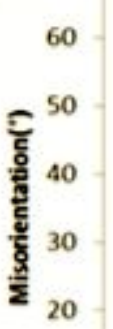

10

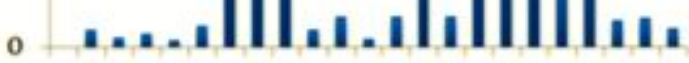

$\begin{array}{llllllllllll}0 & 1 & 3 & 4 & 5 & 6 & 8 & 9 & 10 & 11 & 13 & 14\end{array}$ Distance $(\mu \mathrm{m})$ (b)

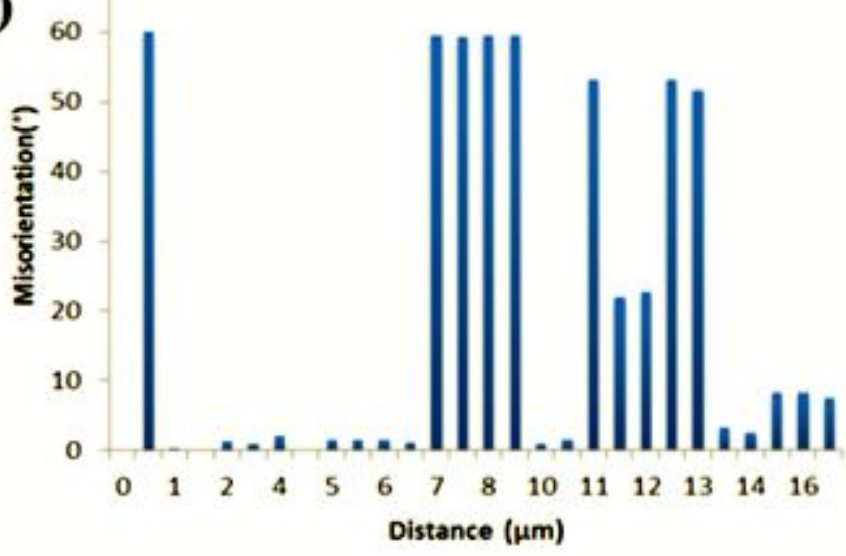

(d)

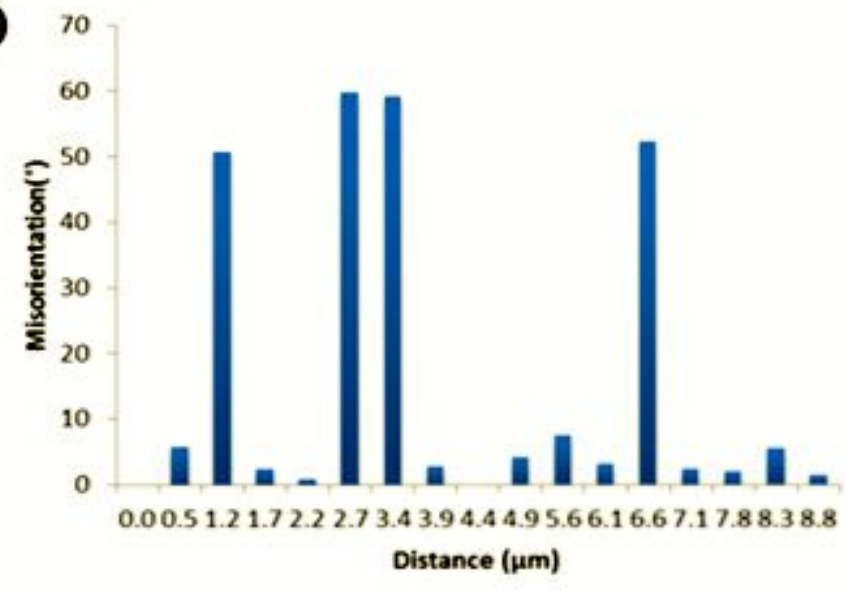


Tool path direction
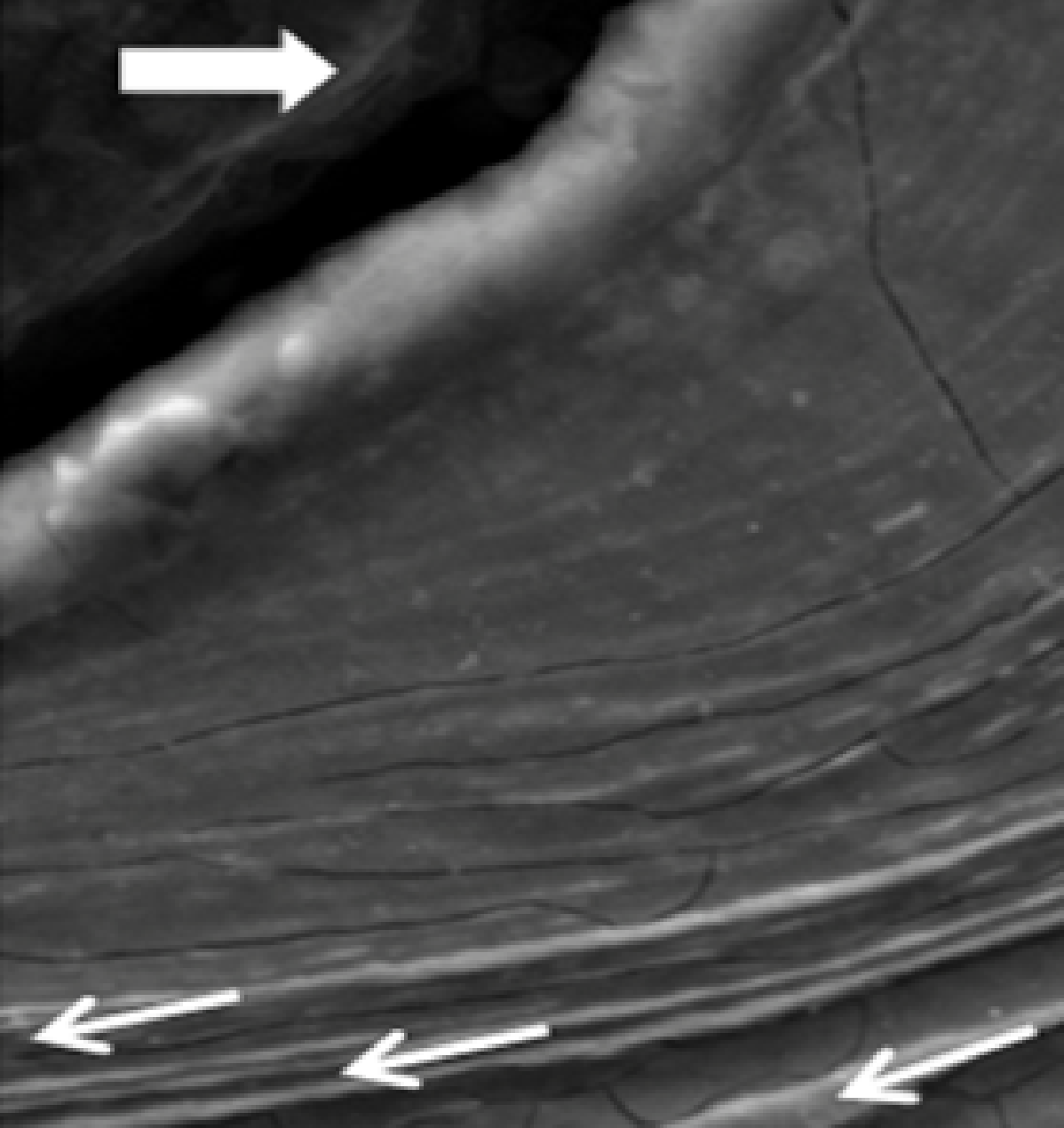

HV Spot WD Det Mag $20.0 \mathrm{kV} 4.010 .4 \mathrm{~mm}$ ETD $6000 \mathrm{x}$

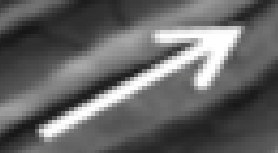




\section{Grain boundary}
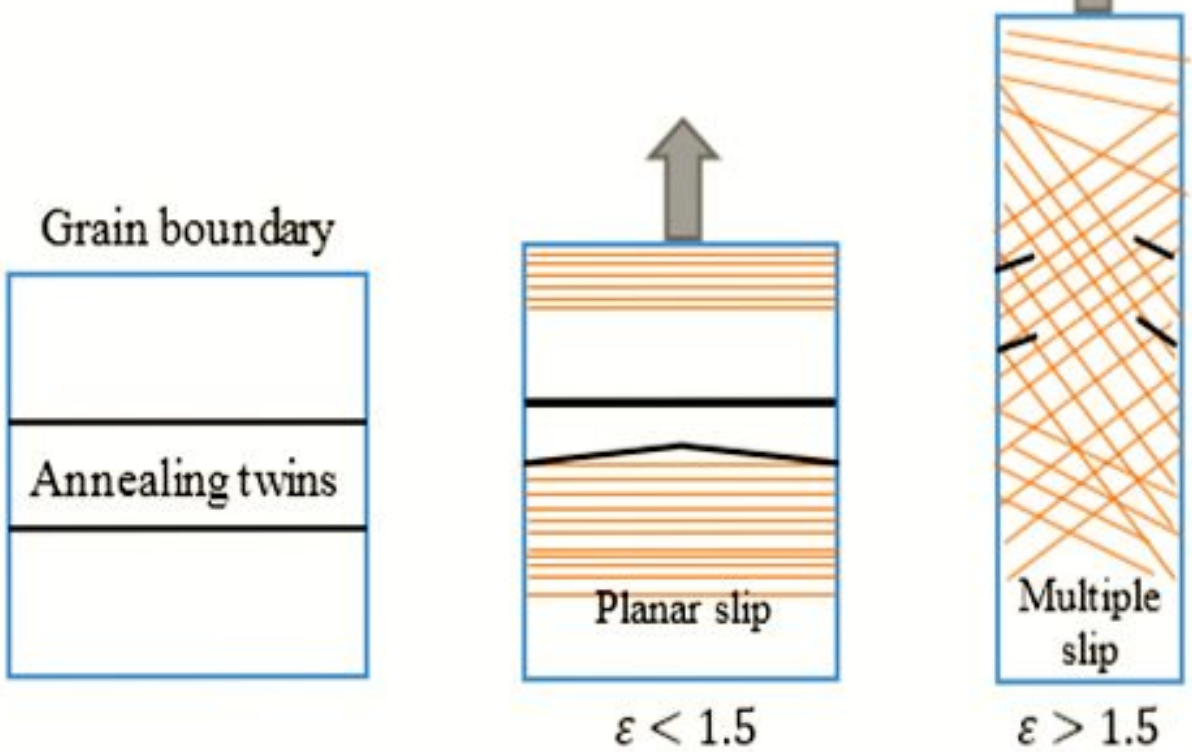

\section{Initial microstructure}

Loading 